\title{
Alüminyum-karbon elyaf sandviç kompozit levhaların V-bükme işleminde bükme açılarının ve bükme yönlerinin geri esneme üzerindeki etkisi
}

\author{
Ali IŞIKTAŞ1,*, Vedat TAŞKIN² \\ ${ }^{1}$ Tekirdağ Namık Kemal Üniversitesi, Hayrabolu MYO. Makina Bölümü̈., Tekirdă̆ \\ ${ }^{2}$ Trakya Üniversitesi, Mühendislik Fakültesi, Makina Müh. Bölümü, Edirne \\ Geliş Tarihi (Received Date): 12.09.2019 \\ Kabul Tarihi (Accepted Date): 01.12.2019
}

$\ddot{\mathbf{O} z}$

$B u$ çalışmada, alüminyum-karbon elyaf sandviç levhaların $V$ bükme operasyonu neticesinde oluşan geri esneme davranışı deneysel olarak incelenmiştir. Bükme yönünün geri esneme davranışı üzerine olan etkisini incelemek amacıyla farklı bükme yönlerindeki sandviç kompozit levhalar $15^{\circ}, 30^{\circ}, 45^{\circ}, 60^{\circ}, 75^{\circ}$ ve $90^{\circ}$ bükme açılarında şekillendirilmiştir. Farklı bükme yönlerinde şekillendirilen sandviç kompozit levhalarda meydana gelen geri esneme değerlerinin birbirine çok yakın olduğu tespit edilmiştir. Ayrıca, T1 (saat yönünün tersinde) bükme yönündeki sandviç kompozit levhaların $75^{\circ}$ ve $90^{\circ}$ bükme açllarındaki testlerinde alüminyum ve karbon elyaf plakalar arasinda açılmalar görülürken, T2 (saat yönünde) bükme yönündeki sandviç kompozit levhaların $75^{\circ}$ ve $90^{\circ}$ bükme açılarında ise dış taraftaki alüminyum sac levhalarda yırtılmalar oluşmuştur.

Anahtar kelimeler: Sandviç kompozit levha, v bükme, geri esneme, bükme yönü.

\section{Effect of bending angles and bending directions on springback in} $\mathrm{V}$-bending of aluminum-carbon fiber sandwich composite plates

\begin{abstract}
In this study, the springback behavior that occurs as a result of $V$-bending operation of aluminum-carbon fiber sandwich plates is examined experimentally. In order to examine the effect on the springback behavior of the bending direction, sandwich composite plates in bending directions $T 1$ and $T 2$ were shaped at the bending angles of
\end{abstract}

\footnotetext{
*Ali IŞIKTAŞ, aisiktas@nku.edu.tr, http://orcid.org/0000-0003-1532-4465

Vedat TAŞKIN, vedattaskin@trakya.edu.tr, http://orcid.org/0000-0002-3013-2317
} 
$15^{\circ}, 30^{\circ}, 45^{\circ}, 60^{\circ}, 75^{\circ}$ and $90^{\circ}$. It was found that the springback values that occurred in sandwich composite plates that were shaped in different bending directions were very close. In addition, while separations between aluminum and carbon fiber plates were found in tests performed at $75^{\circ}$ and $90^{\circ}$ of bending angles in $\mathrm{Tl}$ (anticlockwise) bending direction, the aluminum sheet metals on the outer part were partly cracks at $75^{\circ}$ and $90^{\circ}$ of bending angles in $T 2$ (clockwise) bending direction.

Keywords: Sandwich composite plate, v bending, springback, bending direction.

\section{Giriş}

Sandviç kompozit yapılar, bileşenlerinin farklı özelliklerinden faydalanmak için sert ve yüksek dayanıma sahip kabuk olarak adlandırılan iki yüzey ile çevrelenmiş, ortasında hafif ve mukavemeti düşük bir çekirdek tabaka kullanılarak tasarlanan kompozit yapılardır [1]. Sandviç kompozit yapıların yüzey tabakalarında genellikle alüminyum, titanyum, çelik, ahşap veya beton kullanılmaktadır. Sandviç kompozit levhaların çekirdek tabakasında ise mantar, plastik, bal peteği formundaki alüminyum veya elyaf türevleri kullanılmaktadır [2].

Sandviç kompozit levhaların yüksek mukavemet ve düşük yoğunluk gibi özelliklerinin yanında korozyon direnci gibi çevresel etkilere karşı dayanımlarından dolayı kullanım alanları artmaya başlamıştır [3]. Metaller ile kıyaslandığında sandviç kompozit levhalar daha hafif ve yüksek yorulma mukavemetine sahip olması sebebiyle özellikle uçak sanayisi, uzay teknolojisi, denizcilik sektörü ve otomotiv sektörü gibi birçok alanda tercih edilmektedir [4-6].

Sandviç kompozit levhaların kullanım alanlarının artmasıyla, kullanıldığı yere göre şekillendirilme ihtiyacı da ortaya çıkmıştır. Sadece karbon elyaf kullanılan yapılar şekillendirildiğinde kırılma ve malzeme yüzeyinde yırtılmalar görülmektedir [7]. Karbon elyafin şekillendirilebilme kabiliyetinin düşük olması bir dezavantaj oluşturmaktadır. Bu dezavantajın üstesinden gelmek için karbon elyaf-metal hibrid kompozitler geliştirilmiştir [8]. Hibrit kompozitlerin dış yüzeyinde kullanılan metal saclar sandviç yapının şekillendirilebilme kabiliyetini arttırmaktadır.

Sandviç kompozit levhalar bükme kalıbında şekillendirildikten sonra kalıp açısından farklı bir açı değerinde çıkmaktadır [9-11]. Bükme işleminde malzemeye uygulanan kuvvet kaldırıldığında, malzemenin elastik davranışı malzemenin esneyerek açılmasına neden olmaktadır. Malzemede oluşan bu olay geri esneme olarak adlandırılmaktadır $[12,13]$.

Kompozit levhaların bükme işlemi sonrası geri esneme miktarı tabakalarda kullanılan elyaf özelliklerine ve katman sayısına göre değişmektedir [14-16]. Ayrıca, kompozit malzemelerde geri esneme miktarı zımba radyüsü, bükme hızı, zımbanın malzeme üzerinde bekleme süresi ve sıcaklık gibi proses değişkenlerine göre farklılık göstermektedir [17,18].

Yapılan deneysel çalışmada, metal sac malzemelerin şekillendirilmesinde karşılaşılan en büyük problemlerden birisi olan geri esneme sorununun yüksek performans ve çevresel etkilere karşı dayanımlarından dolayı tercih sebebi olan sandviç kompozit 
levhalara nasıl etki edeceği araştırılmıştır. Bu bağlamda literatürde problemin çözümüne yönelik teorik ve deneysel çalışmalar incelenmiştir [19,20]. Literatür taraması neticesinde, daha önce sandviç kompozit levhaların şekillendirilmesi sonrası oluşan geri esneme davranışı üzerine çalışmaların literatürde yer aldığı ancak sandviç kompozit levhalarda bükme yönünün geri esnemeye etkisinin henüz çalış1lmamış olduğu görülmüştür. Bu nedenle çalışmada, karbon elyaf ve alüminyum sac levhalardan üretilen sandviç kompozit levhaların şekilendirilmesinde bükme yönünün geri esnemeye etkisi araştırılmıştır.

\section{Deneysel çalışma}

\subsection{Materyal ve metot}

Bükme deneylerinde, 30x60 mm boyutlarında sandviç kompozit levhalar kullanılmıştır. Sandviç kompozit levhanın alt ve üst tabakalarında farklı kalınlıklarda (0.6 ve $1.2 \mathrm{~mm})$ Al-5754-H22 alüminyum sac levhalar bulunmaktadır. Al-5754-H22'nin mekanik özellikleri Tablo 1'de verilmiştir.

Tablo 1. Al-5754-H22'nin mekanik özellikleri

\begin{tabular}{|l|l|l|l|}
\hline $\begin{array}{l}\text { Elastisite Modülü } \\
(\mathrm{GPa})\end{array}$ & $\begin{array}{l}\text { Çekme Mukavemeti } \\
(\mathrm{MPa})\end{array}$ & $\begin{array}{l}\text { Yüzde uzama } \\
(\%)\end{array}$ & Sertlik \\
\hline 68 & 245 & 15 & $65 \mathrm{HB}$ \\
\hline
\end{tabular}

Sandviç kompozit levhaların orta tabakasında düz dokuma prepreg karbon elyaf kumaşlardan üretilen karbon elyaf plakalar bulunmaktadır. Elyaf malzeme olarak \% 3537 reçine içeren $93 \mathrm{gr} / \mathrm{m}^{2}$ [0/90]s karbon elyaf kumaş kullanılmıştır. Alüminyum sac levha ve karbon elyaf plakanın yapıştırılması ile sandviç kompozit levha oluşturulmuştur. Sandviç kompozit levhayı oluşturan karbon elyaf plaka ve alüminyum sac levhanın birleştirilmesine ait şema Şekil 1'de gösterilmiştir. Al-5754-H22 sac ve karbon elyaf plakaların birleştirilmesinde Devcon marka Plastic Welder cinsi metakrilat bazlı yapıştırıcı kullanılmıştır. Yapıştırma işleminde kullanılan kalıp sayesinde tüm yüzeylerde eşit $0.3 \mathrm{~mm}$ yapıştırıcı kalınlığı elde edilmiştir [21].

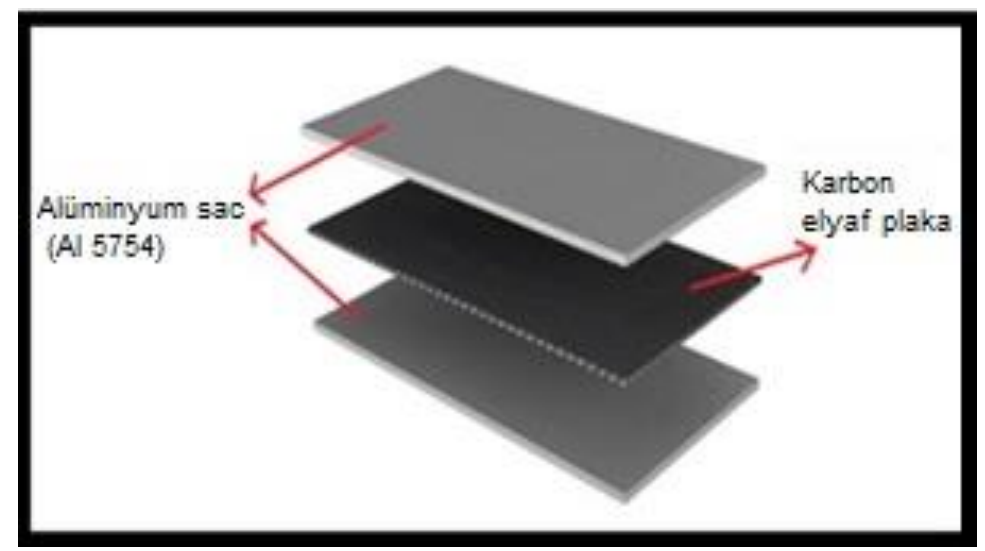

Şekil 1. Sandviç kompozit levhaların oluşumu

Bükme yönleri farklı olan sandviç kompozit levhalar T1 ve T2 olarak isimlendirilmiştir. T1 bükme yönündeki numunelerin üst yüzeyinde $0.6 \mathrm{~mm}$ ve alt yüzeyinde $1.2 \mathrm{~mm}$ kalınlığında Al-5754-H22 bulunmaktadır. T2 bükme yönündeki numunelerin üst 
yüzeyinde $1.2 \mathrm{~mm}$ ve alt yüzeyinde $0.6 \mathrm{~mm}$ kalınlığında Al-5754-H22 bulunmaktadır. Karbon elyaf kalınlığı ise T1 ve T2 de eşit 0.15 mm kullanılmıştır. Bükme yönünün geri esneme miktarına etkisini incelemek amacıyla T1 ve T2 bükme yönlerindeki sandviç kompozit levhalar $15^{\circ}, 30^{\circ}, 45^{\circ}, 60^{\circ}, 75^{\circ}$ ve $90^{\circ}$ bükme açılarında şekillendirilmiştir. Sandviç kompozit levha tabakalarının kalınlıkları ve yerleşim planı Tablo 2'de verilmiştir.

Tablo 2. Sandviç kompozit levha tabakalarının kalınlıkları ve yerleşim planı.

\begin{tabular}{|c|c|c|}
\hline Sandviç kompozit levha & T1 (Saat yönünün tersinde) & T2 (Saat yönünde) \\
\hline Üst yüzey & $0.6 \mathrm{~mm} \mathrm{Al5754}$ & $1.2 \mathrm{~mm}$ Al5754 \\
\hline Orta yüzey & $0.15 \mathrm{~mm}$ Karbon elyaf & $0.15 \mathrm{~mm}$ Karbon elyaf \\
\hline Alt yüzey & $1.2 \mathrm{~mm}$ Al5754 & $0.6 \mathrm{~mm}$ Al5754 \\
\hline
\end{tabular}

Bükme deneyleri, Trakya Üniversitesi Teknoloji Araştırma ve Geliştirme Uygulama ve Araştırma Merkezi'nde bulunan TA.HDPlus marka tekstür analiz cihazında gerçekleştirilmiştir. Deneysel çalışmaların yapıldığı bükme kalıbı ve deney düzeneğinin genel görüntüsü Şekil 2'de verilmiştir.

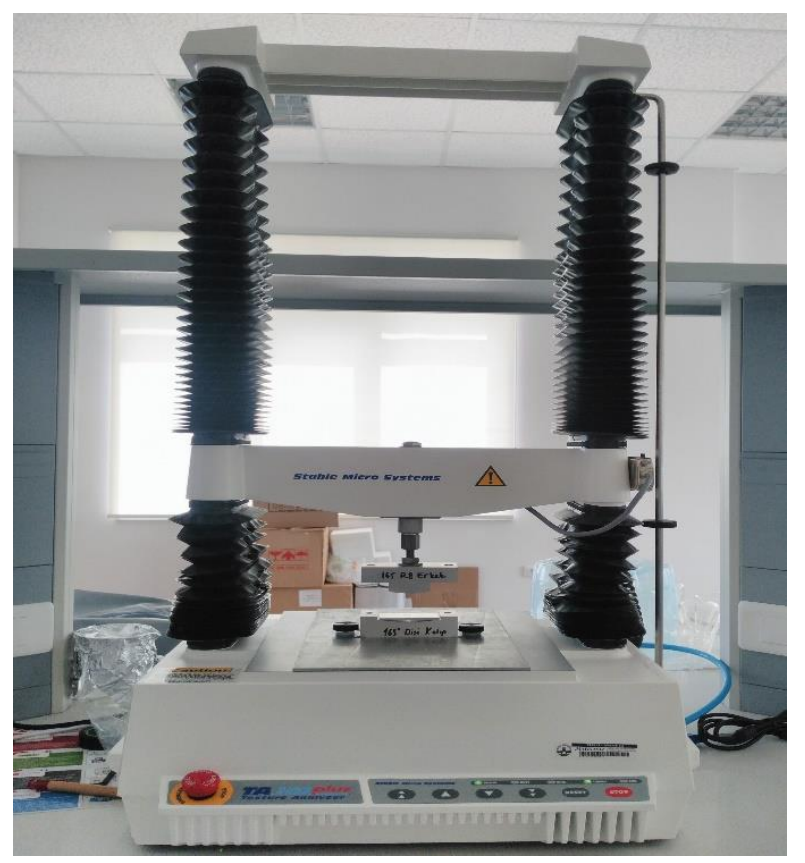

Şekil 2. Bükme deney düzeneğinin genel görüntüsü

V bükme deneylerinde, ilk olarak şekillendirilecek sandviç kompozit levha kalıba yerleştirmiştir. Kalıplar tasarlanırken sandviç kompozit levhaların konulacağı yer, numune boyutundan $1 \mathrm{~mm}$ geniş yapıldığı için numune kalıp boşluğuna düzgün bir şekilde yerleşmektedir. Bu sayede, yapılan her bükme testinde malzemenin konumu aynı olmaktadır. Tekstür cihazının bağlı olduğu bilgisayar yazılımına, sandviç kompozit levha kalınlığ 1 dikkate alınarak basma yüksekliği değeri girilmiştir. Yazılıma girilmesi gereken basma yüksekliği, bükme hızı vb. tüm veriler girildikten sonra bükme testlerine başlanmıştır. Bükme işlemi, zımba ile dişi kalıp arasında malzeme kalınlığı kadar mesafe kalana kadar devam etmektedir. Bükme işlemi esnasında, zımba ile dişi kalıp arasında sandviç kompozit levha kalınlığı kadar boşluk bırakılarak numunenin ezilerek 
deformasyona uğraması engellenmiștir. $\mathrm{V}$ bükme işleminin tamamlanmasıyla sandviç kompozit levhada geri esneme oluşmaktadır. Sandviç kompozit levhalarda bükme işlemi Şekil 3'de gösterilmiştir.

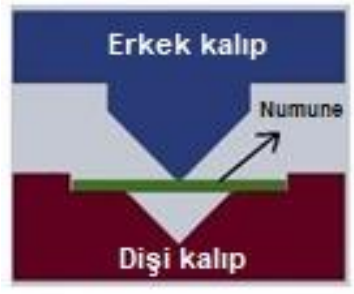

a)

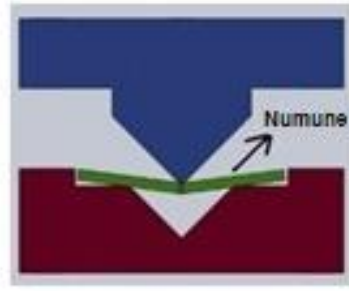

b)

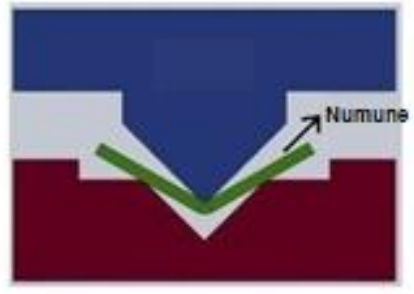

c)

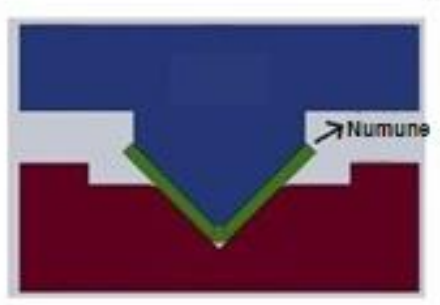

d)

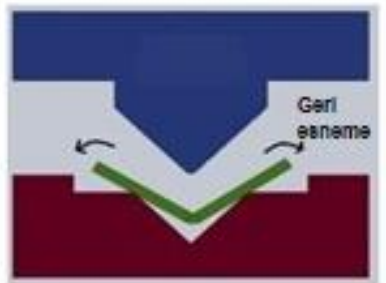

e)

Şekil 3. Sandviç kompozit levhalarda bükme işlemi

Yapılan tüm deney serilerinde bükme hızı $5 \mathrm{~mm} / \mathrm{s}$ ve zımba uç yarıçapı R8 mm olarak sabit seçilmiştir. Her deney aynı özellik ve ölçülere sahip 5 numune kullanılarak tekrarlanmıştır.

Bükme işlemi sonrası sandviç kompozit levha numunelerinin açıları Zeiss Pmc 500 koordinat ölçüm cihazı (CMM) kullanılarak hassas olarak ölçülmüştür. Ölçme işleminde, ölçme cihazının probu sandviç kompozit levhanın bir büküm yüzeyindeki dört farklı noktaya değdirilerek bir düzlem oluşturulmuştur. Aynı işlemi bu sefer numunenin diğer büküm yüzeyindeki dört farklı noktaya prob temas ettirilerek ikinci bir düzlem elde edilmiştir. Elde edilen bu iki düzlem arasındaki açı ölçülerek geri esneme açısı elde edilmiştir.

\subsection{Sandviç kompozit levhaların şekillendirilmesiyle oluşan geri esneme sonuçları}

Sandviç kompozit levhaların farklı bükme açılarında şekillendirilmesi sonrası meydana gelen geri esneme miktarları grafikler üzerinde gösterilmiştir. T1 bükme yönündeki sandviç kompozit levhaların farklı bükme açılarında $\left(15^{\circ}, 30^{\circ}, 45^{\circ}, 60^{\circ}, 75^{\circ}\right.$ ve $\left.90^{\circ}\right)$ şekillendirilmesiyle oluşan geri esneme sonuçları Şekil 4'de verilmiştir. 


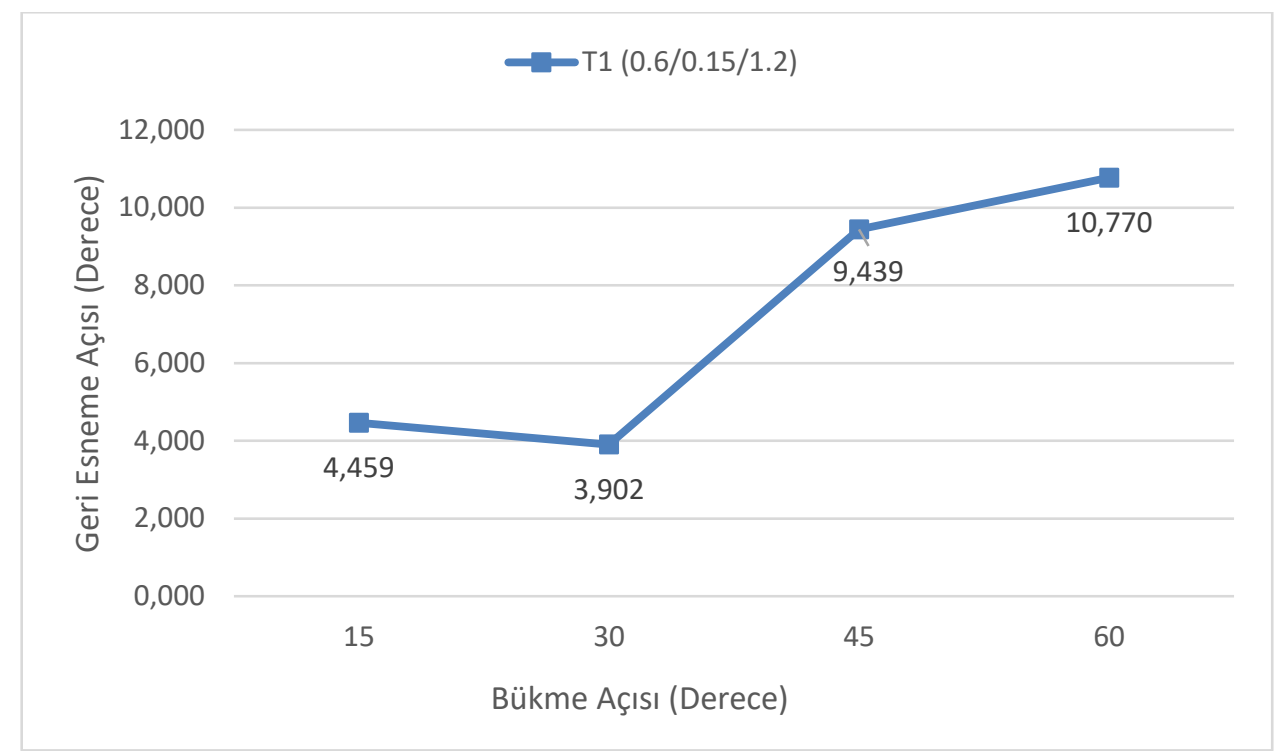

Şekil 4. T1 bükme yönündeki sandviç kompozit levhaların farklı bükme açılarında şekillendirilmesiyle oluşan geri esneme sonuçları

T1 bükme yönündeki sandviç kompozit levhaların $75^{\circ}$ ve $90^{\circ}$ bükme açılarındaki testlerinde alüminyum ve karbon elyaf plakalar arasında açılmalar görülmüştür. $75^{\circ}$ ve $90^{\circ}$ bükülen numunelerin sandviç yapısında açılmalar olduğu için geri esneme değerlendirmesine dahil edilmemiştir. Açılma sebebi olarak, bükme işlemi sırasında alüminyum ve karbon elyaf levhalar arasında oluşan gerilmelerin yapıştırma bağlantı dayanımından daha fazla olduğu söylenebilir. $75^{\circ}$ ve $90^{\circ}$ bükülen numunelerde oluşan açılmalar Şekil 5'de gösterilmiştir.

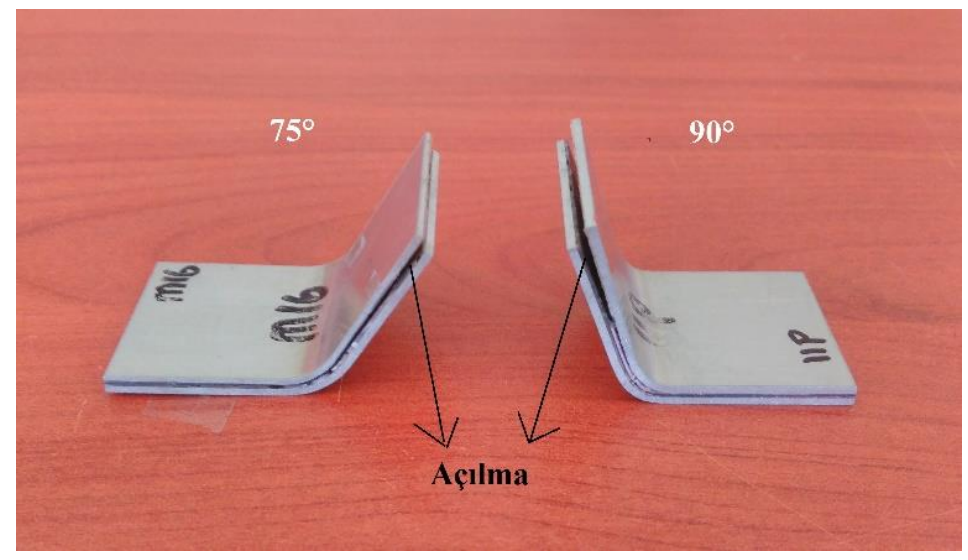

Şekil $5.75^{\circ}$ ve $90^{\circ}$ bükülen numunelerde oluşan açılmalar

T2 bükme yönündeki sandviç kompozit levhaların farklı bükme açılarında $\left(15^{\circ}, 30^{\circ}\right.$, $45^{\circ}, 60^{\circ}, 75^{\circ}$ ve $90^{\circ}$ ) şekillendirilmesiyle oluşan geri esneme sonuçları Şekil $6^{\prime}$ da verilmiştir. 


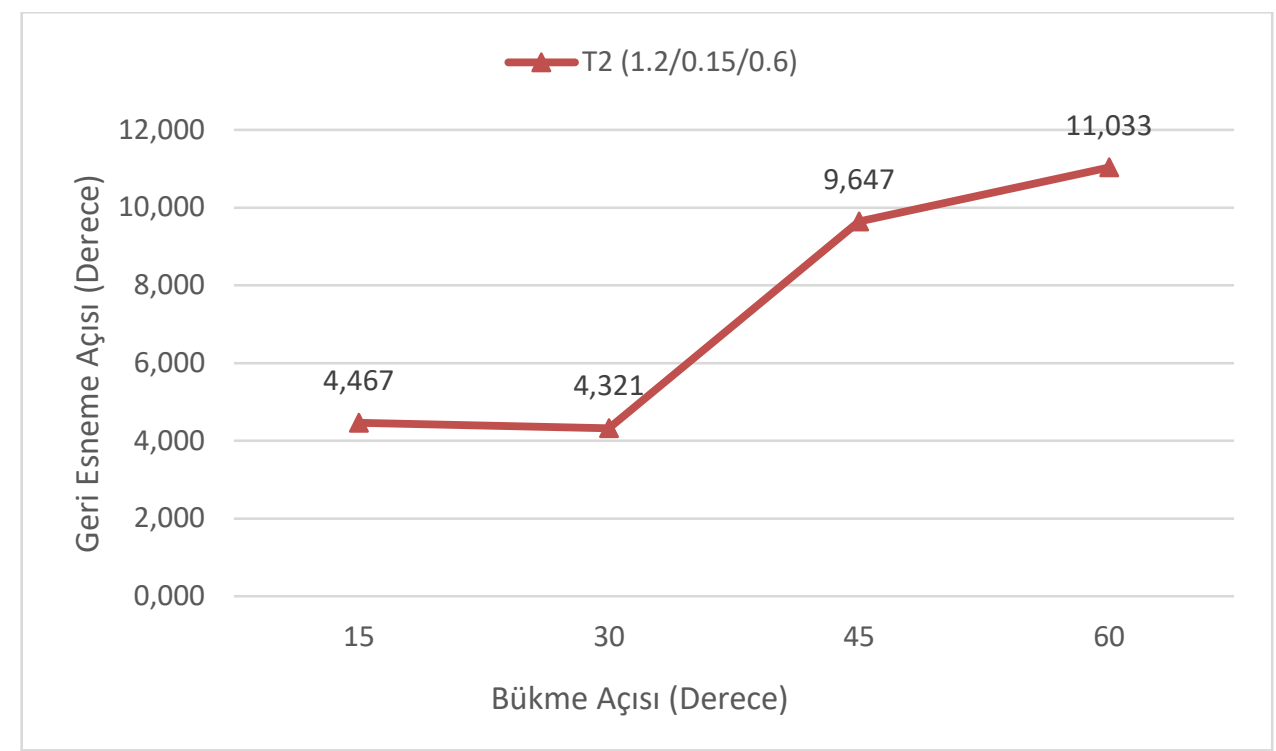

Şekil 6. T2 bükme yönündeki sandviç kompozit levhaların farklı bükme açılarında şekillendirilmesiyle oluşan geri esneme sonuçları

T2 bükme yönündeki sandviç kompozit levhaların $75^{\circ}$ ve $90^{\circ}$ bükme açılarındaki testlerinde ise dış taraftaki alüminyum sac levhalarda yırtılmalar oluşmuştur. $75^{\circ}$ ve $90^{\circ}$ bükülen numunelerin sandviç yapısında yırtılmalar olduğu için geri esneme değerlendirmesine dahil edilmemiştir. Yırtılmanın sebebi olarak, $0.6 \mathrm{~mm}$ kalınlığındaki alüminyum sac malzemenin çekme dayanımının bükme işlemi esnasında kesitte oluşan çekme gerilme değerinden düşük olduğu söylenebilir. $75^{\circ}$ ve $90^{\circ}$ bükülen numunelerde oluşan yırtılmalar Şekil 7'de gösterilmiştir.

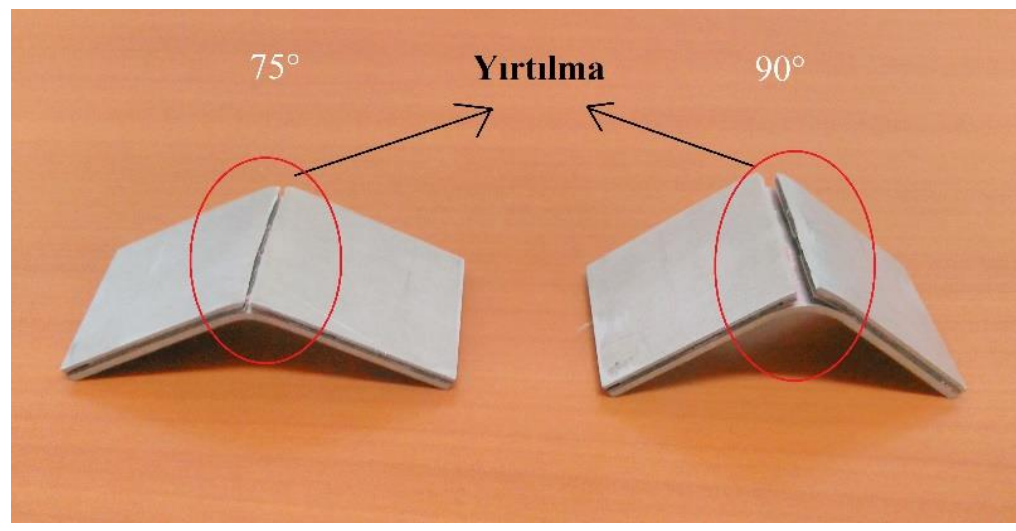

Şekil $7.75^{\circ}$ ve $90^{\circ}$ bükülen numunelerde oluşan yırtılmalar

Sandviç kompozit levhalarda, bükme yönünün geri esneme miktarına etkisini incelemek amacıyla, T1 ve T2 bükme yönündeki sandviç kompozit levhaların farklı bükme açılarında $\left(15^{\circ}, 30^{\circ}, 45^{\circ}, 60^{\circ}, 75^{\circ}\right.$ ve $\left.90^{\circ}\right)$ şekillendirilmesiyle oluşan geri esneme sonuçları Şekil 8 'de karşılaştırılmıştır. 


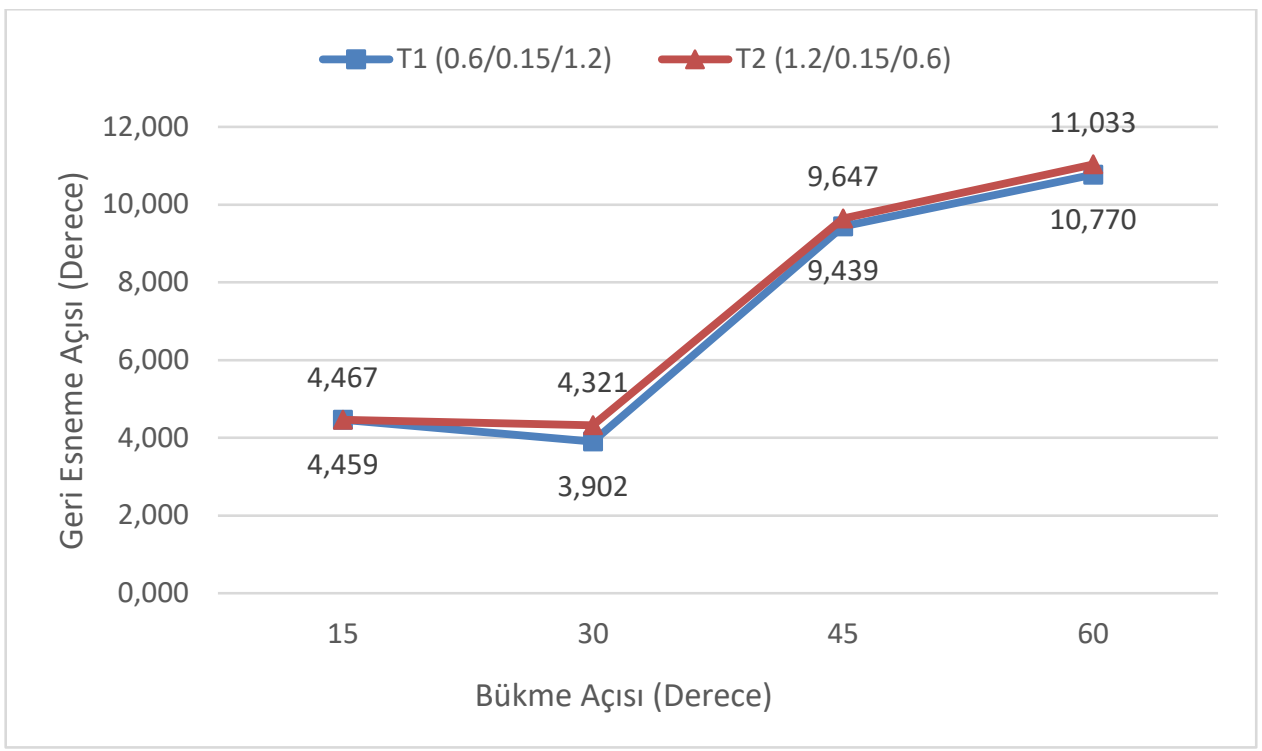

Şekil 8. Farklı bükme yönlerinde şekillendirilen sandviç kompozit levhalarda geri esneme davranışının karşılaştırılması

Şekil 8 incelendiğinde, T1 ve T2 bükme yönündeki tüm sandviç kompozit levhalarda geri esneme meydana gelmiştir. T1 ve T2 bükme yönündeki sandviç kompozit levhalarda meydana gelen geri esneme değerlerinin birbirine yakın olduğu görülmüştür.

\section{Sonuçlar ve tartışma}

Alüminyum-karbon elyaf sandviç kompozit levhaların $\mathrm{V}$ bükme kalıbı ile şekillendirilmesinde bükme yönü ve bükme açısının geri esneme davranışına etkisi incelenmiştir.

- Bükme açısı değiştikçe sandviç kompozit levhalarda meydana gelen geri esneme değerleri değişmiştir.

- Sandviç kompozit levhaların farklı bükme yönlerinde (T1 ve T2) şekillendirilmesi neticesinde, her iki bükme yönünde şekillendirilen tüm sandviç kompozit levhalarda geri esneme meydana gelmiştir (Şekil 4, 6).

- $\quad$ T1 ve T2 bükme yönündeki sandviç kompozit levhalarda meydana gelen geri esneme değerlerinin birbirine yakın olduğu tespit edilmiştir (Şekil 8).

- Bükme açısı arttırıldığında, sandviç kompozit levhalarda bükme yönüne bağlı olarak farklı hasarlar oluşmuştur.

- T1 bükme yönündeki sandviç kompozit levhaların $75^{\circ}$ ve $90^{\circ}$ bükme açılarındaki testlerinde alüminyum ve karbon elyaf plakalar arasında açılmalar görülmüştür (Şekil 5).

- T2 bükme yönündeki sandviç kompozit levhaların $75^{\circ}$ ve $90^{\circ}$ bükme açılarındaki testlerinde ise alüminyum ve karbon elyaf plakalar arasında yırtılmalar oluşmuştur (Şekil 7).

\section{Teşekkür}

Bu çalışma Trakya Üniversitesi Bilimsel Araştırma Projeleri Koordinasyon Birimince desteklenmiştir. Proje numarası: 2017/185. 


\section{Kaynaklar}

[1] Aghchai, A. J., Abolghasemi, A., Moradkhani, B. ve Tajik, M., Experimental, theoretical and numerical investigation of springback behavior of $\mathrm{Al} /$ composite/Al sandwich sheet, Journal of Sandwich Structures \& Materials, 19(6), 659-678, (2016).

[2] Davies, J. M., Lightweight sandwich construction, Cib Working Commission, (2008).

[3] Keipour, S. ve Gerdooei, M., Springback behavior of fiber metal laminates in hat-shaped draw bending process: experimental and numerical evaluation, The International Journal of Advanced Manufacturing Technology, 100(5-8), 1755-1765, (2019).

[4] Mohammadi, S. V., Parsa, M. H. ve Aghchai, A. J., Simplified springback prediction in Al/PP/Al sandwich air bending, Journal of Sandwich Structures \& Materials, 17(3), 217-237, (2015).

[5] Rao, M. D., Recent applications of viscoelastic damping for noise control in automobiles and commercial airplanes, Journal of Sound and Vibration, 262(3), 457-474, (2003).

[6] Uriya, Y. ve Yanagimoto, J., Suitable structure of thermosetting CFRP sheet for cold/warm forming, International Journal of Material Forming, 9(2), 243252, (2016).

[7] Uriya, Y., Ikeuch, K. ve Yanagimoto, J., Cold and warm V-bending test for carbon-fiber-reinforced plastic sheet, Procedia Engineering, 81, 1633-1638, (2014).

[8] Huang, Z., Sugiyama, S. ve Yanagimoto, J., Hybrid joining process for carbon fiber reinforced thermosetting plastic and metallic thin sheets by chemical bonding and plastic deformation, Journal of Materials Processing Technology, 213(11), 1864-1874, (2013).

[9] Kim, S. Y., Choi, W. J. ve Park, S. Y., Spring-back characteristics of fiber metal laminate (GLARE) in brake forming process, The International Journal of Advanced Manufacturing Technology, 32(5-6), 445-451, (2007).

[10] Parsa, M. H., Mohammadi, S. V. ve Aghchai, A. J., Al3105/polypropylene/A13105 laminates springback in V-die bending, The International Journal of Advanced Manufacturing Technology, 75(5-8), 849-860, (2014).

[11] Han, P., Butterfield, J., Price, M., Murphy, A. ve Mullan, M., Part Form Prediction Methods for Carbon Fibre Reinforced Thermoplastic Composite Materials, In Proceedings of the 18th International Conference on Composite Materials (ICCM-18). Jeju Island, Korea, (2011).

[12] Jalali Aghchai, A., Abolghasemi, A., Moradkhani, B. ve Tajik, M., Experimental, theoretical and numerical investigation of springback behavior of Al/composite/Al sandwich sheet, Journal of Sandwich Structures \& Materials, 19(6), 659-678, (2017).

[13] Ján, S. ve Miroslav, J., Springback prediction in sheet metal forming processes, Journal for Technology of Plasticity, 37(1), (2012).

[14] Choi, S. W., Lee, M. S. ve Kang, C. G., Effect of process parameters and laminating methods on spring-back in V-bending of CFRP/CR340 hybrid composites, International Journal of Precision Engineering and Manufacturing, 17(3), 395-400, (2016). 
[15] Yanagimoto, J. ve Ikeuchi, K., Sheet forming process of carbon fiber reinforced plastics for lightweight parts, CIRP annals, 61(1), 247-250, (2012).

[16] Mahzan, A. B. C., Malingam, S. D., Selamat, M. Z. B. ve Said, R. B., A study on the mechanical and forming performance of oil palm fiber reinforced polypropylene composite, American-Eurasian Journal of Sustainable Agriculture, 141-148, (2014).

[17] Hahn, M., Ben Khalifa, N., Weddeling, C. ve Shabaninejad, A., Springback Behavior of Carbon-Fiber-Reinforced Plastic Laminates With Metal Cover Layers in V-Die Bending, Journal of Manufacturing Science and Engineering, 138(12), (2016).

[18] Engel, B. ve Brühmann, J., Spring-in characteristics of thermoplastic composites with glass fiber fabric reinforcement, In Proceedings of the19th International Conference on Composite Materials (ICCM-19), Montréal, Canada, (2013).

[19] Han, P., Butterfield, J., Buchanan, S., McCool, R., Jiang, Z., Price, M. ve Murphy, A., The prediction of process-induced deformation in a thermoplastic composite in support of manufacturing simulation, Proceedings of the Institution of Mechanical Engineers, Part B: Journal of Engineering Manufacture, 227(10), 1417-1429, (2013).

[20] Liu, L. ve Wang, J., Modeling springback of metal-polymer-metal laminates, Journal of manufacturing Science and Engineering, 126(3), 599604, (2004).

[21] Urkmez Taskin, N. ve Sahin, A., Effect of Aging Time at High Temperature on the Shear Strength of Adhesively Bonded Aluminum Composite Foam Joints, The Journal of Adhesion, 95(4), 308-324, (2019). 